\title{
Las Jurisdicciones de Excepción en Francia
}

Los debates que precedieron recientemente la aprobación por e! Parlamerito francés de la Ley que instiiuye el Tribunal de Seguridad del Estado han puesto en el primer plano de la actualidad la cuestión de las juriedie -ciones de excepción en materia represiva. Las soluciones que el legislador trancés debió adoptar bajo la presión de las circunstancias durante los años pasacios forman un conjunto complejo. No parece inútil dar de ellas un cuadro, por lo demás esquemático, para situar las últimas medidas legislativas en relación con las precedentes.

Recordemos primero algunos datos elementales sobre la organización judicial francesa en materia penal. A la clasificación tripartita de las infracciones corresponde la organización en tres categorías de las jurisdicciones ordinarias. Las infracciones más graves, llamadas "crímenes", son sancicnadas por las rours d'assises. Los tribunales correccionales juzgan las infracciones por las que se incurre en penas cortas de prisión o multas; son los llamados "delitos". Las infracciones de poca importancia denominadas "contravenciones" son examinadas por los tribunales de policía. En el sistema tradicional francés las jurisdicciones de excepción sólo tienen en la esfera penal una función episódica. Nos limitaremos a recordar el Alto Tribunal de Justicia, competente para juzgar al jefe del Estado o a los ministros en caso de alta traición. Más importantes desde un punto de vista práctico son los tribunales militares, denominados en la actualidad "tribunales permanentes de las fuerzas armadas", que juzgan a los militares por las infracciones cometidas en acto de servicio o con ocasión del servicio. El procedimiento seguido ante estas jurisdicciones se define en el "Código de Justicia Militar", que es un sector grandemente autónomo del derecho penal francés, pero que recoge en gran medida los principios fundamentales del derecho general $y$, concretamente, la garantía de los derechos de la defensa.

El Código de procedimiento penal, que entró en vigor en diciembre de 1958 después de la refundición del viejo Código de instrucción criminal, reproducía en los artículos 697 a 706 las disposiciones puestas en vigor por el decreto de 29 de julio de 1939, según las cuales los tribunales de las fuerzas armadas tienen además competencia para juzgar, tanto en tiempo de paz como de guerra, los crímenes y delitos contra la seguridad exterior del Estado, salvo algunas excepciones relacionadas con los celitos come- 
tidos en tiempo de paz. Los hechos ocurridos en los departamentos de Argelia a partir del $1^{9}$ de noviembre de 1954 forzaron al Gobierno francés a aumentar esta brecha en la competencia de las jurisdicciones ordinarias. Una ordenanza de 8 de octubre de 1958 amplió considerablemente la competencia de los tribunales de las fuerzas armadas y les atribuyó la sar:ción de una serie de crímenes y delitos cometidos "con vistas a prestar ayuda directa o indirecta a los rebeldes de los departamentos argelinos". La tendencia se acentuó con la ordenanza de 4 de junio de 1960, en la que se borró la distinción fundamental entre la seguridad exterior y la seguridad Interior del Estado. Paralelamente, un decreto de 12 de febrero de 1960 y unc ordenanza de 3 de junio de 1960 instituían procedimientos nuevos, expeditivos y sobremanera restrictivos de los derechos de la defensa; el primero ante los tribunales militares de Argelia y la segunda ante todos los tribunales militares, comprendidos los de la metrópoli, que entendieran en crímenes relacionados con el levantamiento de Árgelia.

Estos últimos textos entraron en vigencia en el preciso momento en que la esperanza de una solución pacífica del problema argelino empezaba a concretarse; la declaración en que el general de Gaulle, el 16 de setiembre de 1959, enunció el derecho del pueblo argelino a la libre determinación marcó el momento decisivo. En este momento se vio también que la subversión pasaba de un campo a otro. Agrupaciones de inspiración neofascista se formaron en Argelia $y$ en la metrópoli con el apoyo más o menos explícito de la extrema derecha parlamentaria $y$ de una parte de los jefes del ejército, con el objetivo abiertamente declarado de hacer fracasar la política liberal del jefe del Estado. La sublevación de una parte de la población europea en Argel el 24 de enero de 1960 fue el primer .estallido. Después de la rendición de los insurrectos, se formó proceso a los responsables civiles y militares de la sedición. El gobierno utilizó los poderes que lo confería la ordenanza de 4 de junio de 1960 para asignar la causa a la jurisdicción militar. Así, correspondió al Tribunal permanente de las fuerzas armadas de París entender en el proceso llamado "de las barricadas" cuyas audiencias llenaron toda su actividad durante varios meses.

Hasta entonces había bastado al Gobierno francés apuntar contra los adversarios europeos de su política en Argelia las armas fabricadas para la lucha contra los nacionalistas argelinos. Sin embargo, con el golpe de fuerza militar de 22 de abril de 1961 en Argel, la subversión entró en una nueva fase. Un directorio de cuatro generales se declaró investido de los poderes civiles y militares en los departamentos de Argelia y apenas disimuló su propósito de extender la insurrección a la metrópoli; mien. tras tanto vacilaba la lealtad del ejército y de la administración. Para atender a la situación, el general de Gaulle dictó el mismo día dos decretos por los que se declaraba el estado de urgencia en el conjunto del territorio metropolitano. El 23 de abril decidió recurrir a los poderes previstos 
en el artículo 16 de la Constitución que autoriza al presidente de la república a tonar "las medidas regueridas por las circunstan cias" cuando las institucionea del país estén "cmenazadas de manera grave e inmediata". El período de aplicación de los poderes excepcionales terminó el 29 de setiembre de 1961, o sea, después de algo más de cinco meses. Ehtretanto dos de los jefes de la insurrección, los generales Maurice Challe y André Zeller, fueron detenidos y transferidos a la metrópoli; la insurrección se había derrumbado. Sin embargo, las fuerzas subversivas no cejaron. Muy al contrario, dieron pruebas de creciente audacia $y$, bajo la nueva denominación de "Organización del Ejército Secreto" (iniciales en francés OAS) extendieron sus ramificaiones en Argelia y en la metrópoli con la benevolencia o la complicidad de elementos del parlamento, la administración y el ejército. Durante el resto de 1961 y todo 1962, multiplicaron los asesinatos, las agresiones y los atentados, crearon en Argelia zonas de disidencia y procuraron desorganizar en la metrópoli los órgcinos y servicins públicos e imponerse por el terror.

Contra esta amencza de gravedad excepcional, el gobierno tenía la obligación de oponerse con procedimientos también excepcionales. La salvacióri del pás exigía que los jefes y los cómplices de la subversión fueran entregados a una justicia firme y rápida. Los tribunales y los procedimientos ordinarios parecían adaptarse mal a las necesidades de la represión. El tribunal de las fuerzas armadas había quedado en una posición descira$\mathrm{d} x$ en el "proceso de las barricadas". Por consiguiente, la solución era crear una o varias jurisdicciones de excepción, que conocieran de los aten. tados contra la seguridad del Estado y de las instituciones mientras existiera lc amenaza de la subversión y cuya composición y funcionamiento se acomodaran a las necesidades de su misión. De hecho, la organización de eatas jurisdicciones de excepsión fue bastante difícil $y$, en menos de dos años, el legislacior tuvo que modificar su estructura en varias ocasiones. Artes de describir los detalles, creemos útil recordar algunas fechas. La historia de las juriscicciones de excepción desde el golpe de fuerza en Argel puede dividirse en tres fases.

Primera fase: El general de Gaulle, en ejercicio de los poderes excepcionales previstos en el artículo 16 de la Constitución, instituye por la decisión de 27 de abril de 1961 el Alto Tribunal Militar y por la de 3 de mayo de 1961 el Tribunal Militar.

Segunda fase: Una ordenanza de 26 de mayo de 1962 suprime el Alto Tribunal Militar; otra de $1^{\circ}$ de junio de 1962 crea el Tribunal Militar de Justicia.

Tercera fase: El Consejo de Estado, por resolución de 19 de octubre de 1962, anula la ordenanza de $1^{\circ}$ de junio de 1962; el 15 de enero de 1963 se promulga la Ley que instituye el Tribunal de Seguridad del Estado.

\section{1}

A primera vista, estos titubeos del legislador desconciertan, pero, bajo la diversidad de las denominaciones, las jurisdicciones que acabamos de 
enumerar tienen caracteres comunes que subrayaremos antes de exponer las particularidades propias de cada una de ellas.

La competencia ratione loci de todas estas jurisdicciones se extiendo al ccnjunto del teritorio francés. En cuanto a su competencia ratione materiae, ésta se concibe según criterios virtualmente idénticos. Subrayemos inmediatamente que, al revés de lo que pudiera dar a entender una terminología un tanto equívoca, el Tribunal Militar no era de ningún modo una jurisdicción inferior, o de primera instancia, respecto al Alto Tribunal Militar: uno y otro conocian de las mismas categorías de infracciones. Según las decisiones de 27 de abril y 3 de mayo de 1961, tenían competencia para juzcar los crímenes y los delitos contra la seguridad del Estado y la disciplina de los ejércitos "cometidos en relación con los hechos osurridos en Argelia... cuando estos crímenes y delitos hayan sido cometidos antes del fin del período de ejercicio de los poderes excepcionales". La definición de su competencia fué precisada luego por una ordenanza de 14 ce abril de ¡962 cuyas estipulaciones fueron reafirmadas para el Tribunal Militar de Justicia y después para el Tribunal de Seguridad del Estado. A la fórmula muy amplia que hace referencia a "los crímenes y delitos contra la seguridad del Estado", se añade una larga lista de infracciones, comprendidos el robo, la estafa y la defrauciación con abuso de confianza, que serán enjuiciadas por las jurisdiciones de excepción si han sido cometicics "en relación con actos individuales o colectivas encaminados o tendentes a sustiluir por una autoridad ilegal la del Estado".

La asignación de causas a estas jurisdicciones obedece a reglas idénticas. Los textos sobre el Tribunal Militar, el Alto Tribunal Militar y el Tribunal Militar de justicia dicen que entienden en las causas "por decreto". En la Ley de 15 de enero de 1963 se dispone que el Tribunal de Seguridad del Esiacio conoce de un asunto por indicación de su ministerio público "previa orden escrita del ministro de Justicia". Aspecto importanie, cortún a estas cuatro jurisdicciones: cuando una de ellas entienda en una causa en las formas indicadas más abajo, cualquier jurisdicción de instrucción - de decisión que haya conocido antes de los mismos hechos pierde su competencia de pleno derecho. En otras palabras, la competencia del tribunal de excepción tiene prioridad sobre la competencia concurrente del tribunal ordinario.

Estas jurisdicciones difieren entre sí sobre todo por su composición. Cabe observar, sin embargo, que - a excepción del Tribunal Militar de Justicia que se componía de cinco militares - el número de magistrados profesionales es igual al de generales o jefes superiores. Por oira parte, es regla constante y sin excepción que los miembros, civiles y militares, que componen estas jurisdicciones sean nombrados por decreto.

El Tribunal de Seguridad del Elstado, creado por la Ley de 15 de enero de 1963, celebró su primera sesión el 26 de febrero. Reemplaza al Tribunal Militar y al Tribunal Militar de Justicia. Así, pues, las jurisdic- 
ciones de excepción se dividen en dos grupos: las que fueron creadas en 1961 y 1962, y la que el legislador ha instituido recientemente para reemplazarlas.

El Tribunal Militar, creado por la decisión de 3 de mayo de 1961 , siguió funcionando hasta ser sustituido por el Tribunal de Seguridad del Estacio el 26 de febrero de 1963. Como hemos visto, su competencia era concurrente con la del Alto Tribunal Militar y del Tribunal Militar de Justicia. Estaba presidido por un magistrado del Tribunal de Casación y estaba formado por varias salas cuyo número se fijó en tres por el decreto de 26 de junio de 1961. Cada una se componía de un magistrado del Tribunirl de Casación o de un tribunal de apelación (que ejercía la presidencia), de un magistrado profesional $y$ de tres generales o jefes superiores. El ministerio físcal estaba bajo la autoridad de un procurador general militar, asistido por magistrados militares. Toda decisión del Tribunal Militar que ver. sara sobre el fondo del proceso podía ser objeto de recurso de casación.

El Alto Tribunal Militar, creado por la decisión de 27 de abril de 1961, estaba presidido por un magistrado de carrera con el rango de presidente de sala o magistrado del Tribunal de Casación. Comprendía ademós a ocho asesores: los generales cancilleres de las Ordenes de la Legión de Honor y de la Liberación, un consejero de Estado, dos presidentes de tri. bunal de apelación o presidentes de sala en el Tribunal de Apelación de París y tres generales. Recordemos que, como los del Tribunal Militar, todos sus miembros eran nombrados por decreto. El ministerio público estaba compuesto por el procurador general ante el Tribunal de Casación asistido por uno o varios fiscales. Según el artículo 8, "no podrá interponerse ningún recurso contra ninguna decisión del Alto Tribunal Militar". Con libertad para atribuir los procesos al Alto Tribunal o al Tribunal Militar, el gobiemo reservó al primero los asuntos más importantes. En particular, se asignó al Alto Tribunal Militar la causa contra los cuatro miembros del efímero directorio de Argel, los generales Maurice Challe y André Zeller primero, Rcoul Salan luego $y$, por último, Edmond Jouhaud. Esta jurisdicción fue suprimida por una ordenanza de 26 de mayo de 1962.

El Tribunal Militax de Justicia, creado por la ordenanza de $1^{\circ}$ de junio de 1962, al contrario de las jurisdicciones precedentes, no comprendía a ningún magistrado profesional. Presidido por un general, estaba formado ac’emás por cuatro oficiales o suboficiales. El ministerio público se conpo. níx de uno o varios oficiales, nombrados por decreto como los jueces. Según el artículo 10, las decisiones del Tribunal, asi como las de su presidente - del ministerio público, no podían ser objeto de recurso. Esta disposición excluía la posibilidad de interponer recurso de casación. Además, pura prevenir las eventuales discusiones a que pudieran dar lugar algunas maniobras de procedimiento, otra ordenanza de $1^{\circ}$ de junio de 1962 excluía formalmente la posibilidad de presentar recurso de revisión.

En adelante, podremos referimos en tiempo pasado, no sólo al Alto Tribunal Militar, sino también al Tribunal Militar $y$ al Tribunal Militar de Justicia que han sido reemplazados por el nuevo Tribunal de Seguridad del Estado. Ahora bien, no carece de interés señalar los caracteres comunes 
del procedimiento que se seguía ante estas tres jurisdicciones. Es cierto que este procedimiento se apartaba considerablemente de las reglas jurídicas normales en la fase de la instrucción y en la de la sentencia.

En materia de instrucción. el derecho penal francés se basa en dos reglas sundamentales: a) En lo criminal, la instrucción previa es obligatoria; b) en lo criminal y también en lo correccional, la responsabilidad de formar causa incumbe a un magistrado de la carrera judicial, cuyas derisiones son actos jurisdiccionales que pueden ser objeto de recurso ante una sala del tribunal de apelación. Desde luego, el ministerio público recibe constantemente informaciones sobre el desarrollo del procedimiento, pero su dirección le es ajena; en suma, el ministerio fiscal propone $y$ el juez de instrucción dispone. El procedimiento especial de las tres jurisdicciones de excepción era. incompatible con estos dos principios. Cuando corisideraba que los hechos estaban suficientemente establecidos, por ejemplo, por la investigación de la policía o de la gendarmería, el ministerio público podía prescindir de la instrucción previa y someter el acusado al tribunal por citación directa. Cuando había lugar a la instrucción previa, ésta incumbía al ministerio público, y era precisamente esto lo que constituía el atentado más grave a los principios generales del procedimiento general: se conferían las responsabilidades $y$, por ende, los poderes del juez de instrucción a los mismos que habian tenido la iniciativa del proceso. Los funcionarios del ministerio fiscal tenían poder para expedir mandamientos de detención y prisión, decidian sin recurso posible las peticiones de libertad provisional, practicaban los interrogatorios, los registros, el examen $y$ el careo de los testigos, $y$ se pronunciaban sobre la conclusión del sumario y la entrega del detenido al órgano de decisión judicial.

El cuanto al procedimiento que debía seguirse ante la jurisdicción que dictaba sentencia, los textos remitían a la ordenanza de 2 de enero de 1959, con fuerza de ley orgánica del Alto Tribunal de Justicia. Según los artículos 33 y 34 de esta ordenanza, las decisiones relativas a la culpabilidaả y a la aplicación de la pena se toman por mayoría absoluta. En cambio, en las jurisdicciones ordinarias, estas decisiones se toman por mayoría calificada. Respecto a la cour d'assises, que es la única jurisdicción ordinaria para la que se plantea la cuestión, esta regla está consignada en el artículo 359 del Código de procedimiento penal, según el cual "toda decisión desfavorable al acusado, comprendida la que niega las circunstancias atenuantes, ha de tomarse por mayoría de ocho votos como mínimo". Dado que la cour d'assises está compuesta por tres magistrados y nueve jurados, bastan cinco votos para impedir la adopción de una decisiór de esta índole. En los tribunales militares que nos ocupan, la sentencia más severa se podía pronunciar por tres votos contra dos.

Dicho esto, tocó al Tribunal Militar de Justicia, en los nueve meses de su existencia, vulnerar la organización judicial. Para empezar, las circurstancias en que fue creado unos días después de la supresión por ordenanza del Alto Tribunal Militar no auguraban nada bueno. No es ningún secreto que la supresión del Alto Tribunal Militar se debió a la sentencia pronumciada en el proceso del general Salan, que tue considerada dema- 
siado indulgente en determinadas esferas. Para reemplazarlo se instituyó un tribunal cuya sentencia era definitiva y contra la que no cabía recurso y del que en principio se había eliminado a los magistrados profesionales. Estc sustitución ab irato de una jurisdicción especial de excepción por otra de atribuciones especiales todavía más amplias no estaba en modo alguno en armonía con las tradiciones del derecho francés.

Ocupado, como antes lo había estado el Alto Tribunal Militar, en los asuntos más importantes, el Tribunal Militar de Justicia pronunció, entre otras, dos penas de muerte, de las que una se llevó a efecto. En ausencia de todo recurso contra las decisiones de esta jurisdicción, el abogado del otro condenado tuvo la idea de impugnar ante el Consejo de Estado la ordenanza del $1^{\circ}$ de junio de 1962 que instituyó el Tribunal Militar de Justicia. Sostuvo que ese texto, al contrario de las decisiones de 27 de abril y 3 de mayo de 1961, había sido dictado fuera del período de vigencia de los "poderes excepcionales" en que era aplicable el artículo 16 de la Constitución y se fundaba solamente en la Ley de 13 de abril de 1962 que autorizaba al presidente de la República a dictar por ordenanza o decreto las medidas legislativas o reglamentarias necesarias para la aplicación de los acuerdos que se acababan de concertar con el Gobierno Provisional de la República Argelina. Al instituir una jurisdicción de excepción, el jefe del Estado había rebasado los límites de esta delegación legislativa. El Consejo de Estado resolvió en asamblea plenaria de lo contencioso el 19 de octubre de 1962 . En los motivos de la resolución, hizo notar que la creación del Tribunal no era en sí misma un acto con exceso de poder, pero que los circunstancias que habían dado lugar a la delegación legislativa no justificaban "la importancia y la gravedad de las violaciones que la ordenanza inflige a los principios generales del derecho penal, particularmente en to que concierne al procedimiento previsto y a la exclusión de toda vía de recurso". Por consiguiente, el Consejo de Estado anuló la ordenanza de 1 ? de junio de 1962.

Esta decisión planteó una cuestión difícil, pues privó al Tribunal Militar de Justicia de existencia legal e invalidó además las sentencias que habian dictado. El presidente de la República, en ejercicio de su derecho de gracia, conmutó la pena de muerte todavía pendiente en una reclusión y el gobierno presentó al parlamento un proyecto de ley que fue aprobado y promulgado el 15 de enero de 1963. Esta fue la Ley que instituyó el Tribunal de Seguridad del Estado. Una de sus disposiciones contirió validez con carácler retroactivo a la ordenanza de $1^{\circ}$ de junio de 1962, así como a "los actos, formalidades y decisiones realizados o adoptados en aplicación de dicha ordenanza".

Estaba justificado suponer que esta disposición sólo se refería $\alpha$ aclos pretéritos; en todo caso, la próxima institución del Tribunal de Seguridad del Estado privaba de toda razón de ser al Tribunal Militar de Justicia. Por eso, causó mucha sorpresa el anuncio, en enero de 1963, de que el jefe del Estado había dictado un decreto por el que transfería al Tribunal Militar de justicia a catorce de los acusados de haber participado en la tertativa de asesinato del presidente de la República, cometida el 22 de 
agosto de 1962. En realidad, el restablecimiento de este Tribunal era manifiestamente incompatible con el espíritu de la Ley de 15 de eners de 1963. En efecto, la existencia del Tribunal dependía de las disposiciones de esta Ley, según la cual el Tribunal Miliiar y el Tribunal iMilitar de Justicia cesarían de existir cuando se establecier,a el Tribunal de Seguridad del Esiado. Esto sentado, era evidente que el juicio iniciado el 28 de enero de 1963 iba a durar varias semanas $y$, sin duda, se prolongaría más allá del 25 de febrero, fecha prevista para la apertura del Tribunal de Seguridad del Estado, que ibx a reemplazar al Tribunal Militar de justicia. Para superar esta dificultad, el gobierno pidió al parlamento que aprobara una ley para modificar la del 15 de enero de 1963 y prolongar la existencia del Tribunal Militar de Justicia hasta el final del juicio en curso. Como resultado de estas prolijas manipulaciones, el Tribunal Militar de Justicia pudo dar cima al juicio el 4 de marzo de 1963. Seis de los acusados fueron condenados a muerte y ocho a diversas penas de prisión. Tres de las penas de muerte fueron pronunciadas in absentia: los otros tres reos se hallaban presentes en el juicio. Uno de ellos fue ejecutado el 11 de marzo; las penas de los otros dos fueron conmutadas en cadena perpetua. Cada uno evaluará a su gusto la decisión de los magistrados militares, pero tratándose del respeto por el imperio de la ley - se ha de deplorar profundamente que esta decisión fuera adoptada por un Tribunal cuya existencia habia sido declarada ilegal por el Consejo de Estado y cuyo funcionamiento subsiguiente er $\alpha$ una afrenta $\alpha$ los principios generalmente aceptados del procedimiento penal.

El Tribunal Militar de Justicia cesó de existir tan pronto como hubo adoptado su decisión del 4 de marzo de 1963. Coexistió durante varios días con el Tribunal de Seguridad del Estado, que empezó a funcionar el 26 de febrero; en adelante, este Tribunal asume in toto las atribuciones do las precedentes jurisdicciones de excepción. En la Ley núm. 63-23 de 15 de enero de 1963 se fijan la organización y las funciones del Tribunal de Seguritad del Estado. Además, por otra Ley, núm. 63-22, también de 15 de enero de 1963, se modifican algunas de las disposiciones del Código penal y del Código de procedimiento penal. Al tomar esta injciativa de reforma legislativa inmediatamente después del referendum y de las elecciones parlamentarias de octubra y noviembre de 1962, en cuya ocasión la mayoría del electorado reafirmó su confianza en el jefe del Estado, el gobiemo ha dado pruebas de su deseo de conciliar la defensa de las instituciones con el restablecimiento del procedimiento penal tradicional. Sin duda, el Tribunal de Seguridad del Estado es una jurisdicción de excepción, pero las normas que rigen su composición y funciones ge inspiran on lo esencial en los principios generalmente aceptados del derecho penal.

El Tribunal está formado por una sala de juicio y una sala de fiscalización de la jurisdicción. La primera, dirigida por el presidente del Tribunal, comprende además a dos magistrados de la carrera judiciál y a 
dos generales $\circ$ jefes superiores. La segunda está compuesta por tres ma:gistrados de carrera. Llegado el caso, el Tribunal podrá ser completado por salas temporales instituidas por decreto y cuya composición será icién.tica a la de la sala de decisión. Los magistrados y oficiales que constituirán: el Tribunal serán nombrados por decreto del Consejo de Ministros para. un periodo de dos años renovable, previo dictamen del Consejo Superior de la Magistratura en lo que concierne a los magistrados. Además, están. adscritos al Tribunal tres jueces de instrucción. El ministerio público comprende a un procurador general y a dos fiscales generales, bajo la autoridad directa del ministro de Justicia. La sede permanente del Tribunal será fijada por decreto. Además, el presidente puede decidir que se reúna en un lugar cualquiera del territorio trancés.

Importe subrayar que las reglas de instrucción son las del derecho ordinario, con algunas excepciones. Assí, la detención preventiva inicial, esto es, la detención de un sospechoso por un oficial de la policía juáicial antes de inculparle y entregarle al juez, que el artículo 63 del Código de procedimiento penal limita a dos días, podrá durar en este caso diez días Los debates judiciales se regirán por las reglas aplicables en el caso de los tribunales correccionales. El Tribunal tomará su decisión según las formalidades seguidas por las cours d'assises. Por último, y sobre todo, se podrá recurrir contra las decisiones del Tribunal ante el de Casación.

En los debates sostenidos en las dos cámaras del parlamento, la composición del Tribunal y las reglas de procedimiento, entre ellas las relativas a la detención preventiva inicial, dieron lugar a extensas discusiones. En lo inmediato, el Tribunal habrá de ocuparse de unas trescientos cincuenta causas que estaban pendientes de instancia ante las anteriores jurisdicciones de excepción. Por supuesto, el porvenir del Tribunal dependerá de la evolución de la situación en Francia. Cuanto antes se anticipe en ese faís la posibilidad de suprimir totalmente las jurisdicciones de excepción. tanto más halagüeñas serán las perspectivas para la cabal restauración del imperio de la ley.

Nota.--Este artículo ha sido redactado por la Comisión Internacional de Juristas, con sede en Ginebra (Suiza). 